\title{
A Case Report of an Uncommon Sex-Cord Stromal Tumor Consisted of Luteal and Sertoli Cells in a Spayed Bitch
}

\author{
Ryohei ICHIMURA ${ }^{1)}$, Makoto SHIBUTANI ${ }^{1) *}$, Sayaka MIZUKAMI ${ }^{1}$, Terumasa SUZUKI $^{1)}$, Yuko SHIMADA ${ }^{1)}$ and \\ Kunitoshi MITSUMORI ${ }^{1)}$ \\ ${ }^{1)}$ Laboratory of Veterinary Pathology, Tokyo University of Agriculture and Technology, 3-5-8 Saiwai-cho, Fuchu-shi, Tokyo 183-8509, \\ Japan
}

(Received 26 May 2009/Accepted 20 September 2009/Published online in J-STAGE 25 November 2009)

\begin{abstract}
We report a rare case of benign sex cord-stromal tumor consisted largely of luteoma with minor portion of Sertoli cell tumor located at the position of the left ovary excision in an 11-year-old ovariectomized bitch. Granulosa cell component was lacking, and both luteal and Sertoli cell portions were entirely positive for inhibin $\alpha$ and neuron-specific enolase, whereas luteoma portion alone was positive for Wilms' tumor-1 (WT1), immunohistochemically. The results suggest that this tumor is a possible complication of incomplete ovarian excision at the time of ovariectomy and consisted of uncommon hybrid of luteal and Sertoli cells to be diagnosed as an unclassified sex cord-stromal tumor if applied in human cases. WT1-expression pattern suggested the signature of the difference in the phenotype of these cell types.
\end{abstract}

KEY WORDS: inhibin $\alpha$, luteoma, Sertoli cell tumor, sex cord-stromal tumor, Wilms' tumor-1 (WT1).

In the old literature, a variety of types of sex cord-stromal tumors have been reported in bitches, such as granulosa cell tumor, Sertoli cell tumor, luteoma, and nonspecific stromal tumor $[2,6,16]$. In a later published retrospective study of 71 primary ovarian tumors in dogs, the incidence of epithelial tumors $(46 \%)$ was slightly higher than that of sex cordstromal tumors $(34 \%)$ or germ cell tumors (20\%) [19]. Sex cord-stromal tumors were then equally divided into SertoliLeydig and granulosa cell tumors, and there was no indication of steroid cell tumors or luteomas. Granulosa cell tumors are usually the group of tumors that include granulosa theca cell tumors, and if they have abundance of lipid, they are diagnosed as luteinized granulosa cell tumors [30]. On the other hand, in humans, occasional tumors are encountered which clearly fall in the sex cord-stromal category but do not lend themselves to placement in the more specific categories, warranting the somewhat unsatisfactory diagnosis of sex cord-stromal tumor unclassified in both male and female gonads [25].

This report describes a case of sex cord-stromal tumor with differentiation into luteal and Sertoli cells in an 11year-old spayed bitch. At one year of age, this dog received ovariectomy for sterilization. At 10 years of age, bloody fluid appeared from valva. By ecography, one splenic tumor and another tumor located at the portion of the excised left ovary attached to the mesovaria were found, and they were then surgically resected. No other abdominal tumors/nodules were found at the surgery. The splenic tumor was histopathologically diagnosed as follicular lymphoma. The ovarian portion tumor consisted of a spherical

\footnotetext{
* Correspondence to: Shibutani, M., Laboratory of Veterinary Pathology, Tokyo University of Agriculture and Technology, 35-8 Saiwai-cho, Fuchu-shi, Tokyo 183-8509, Japan. e-mail:mshibuta@cc.tuat.ac.jp
}

and soft mass showing white and brown patchy pattern on cut surface. The mass was fixed in $10 \%$ neutral buffered formalin for three days at room temperature, trimmed, dehydrated, and paraffin embedded, and $4 \mu \mathrm{m}$ sections were stained with hematoxylin and eosin (HE). As immunohistochemical analyses, avidin-biotin-peroxidase complex (ABC) technique was applied using antibodies against inhibin $\alpha$ (rabbit polyclonal antibody; 1/100 dilution; gift from Dr. Gen Watanabe, Laboratory of Veterinary Physiology, Tokyo University of Agriculture and Technology, Japan) [27], Wilms' tumor-1 (WT1; rabbit polyclonal antibody; 1/100 dilution; Santa Cruz Biotechnology, Inc., Santa Cruz, CA, U.S.A.), neuron-specific enolase (NSE: rabbit polyclonal antibody; 1/100 dilution; Calbiochem, San Diego, CA, U.S.A.), and von Willebrand factor (rabbit polyclonal antibody; 1/200 dilution; Dako, Glostrup, Denmark). All slides were pretreated with citrate buffer $(10 \mathrm{mM}, \mathrm{pH}$ 6.0) for antigen retrieval by heating in an autoclave at $121^{\circ} \mathrm{C}$ for $10 \mathrm{~min}$. After visualization of immunoreactivity with 3,3'-diaminobenzidine $/ \mathrm{H}_{2} \mathrm{O}_{2}$ as the chromogen, these slides were lightly counterstained with hematoxylin. Normal canine testis and ovary each from an adolescent male and a prepubertal infantile female were used as a positive control for immunostainings. Normal rabbit serum was used as a negative control for immunostainings. As a positive control for Sertoli cell tumor, a testicular tumor, diagnosed as malignant Sertoli cell tumor, developed in a male dog of 8 years of age that showed cryptorchidism, was used.

Using cryosections, periodic acid Schiff (PAS) and Sudan IV stainings were performed. Fixed tumor tissue was trimmed, immersed in $30 \%$ sucrose solution for $12 \mathrm{hr}$, embedded in Tissue-Tek 4583 OCT compound (Sakura Finetek Japan, Tokyo, Japan), and then quickly frozen in liquid nitrogen. Using cryotome (Sakura Finetek Japan), 5 
$\mu \mathrm{m}$ sections were prepared at $-30^{\circ} \mathrm{C}$. For PAS staining, sections were treated with $1 \%$ periodic acid solution, and then immersed in Lillie's Schiff reagent for $10 \mathrm{~min}$. After washing with sulfurous acid solution, sections were then stained with hematoxylin. For Sudan IV staining, sections were immersed in $1 \%$ potassium hydroxide solution, replaced the solution with $50 \%$ ethanol, and then immersed in $2 \%$ Sudan IV solution for $30 \mathrm{~min}$, and counterstained with hematoxylin. For color enhancement, the sections were treated for 30 sec with $4 \times$ diluted solution of saturated lithium carbonate stock solution at $60^{\circ} \mathrm{C}$. The PAS staining was also performed in the paraffin embedded tissue sections.

Histologically, the tumor was mainly consisted of round neoplastic cells resembling luteoma cells with centrally located nucleus in abundant vacuolated cytoplasm, forming variable sized cellular nests intersected incompletely with fibrous stroma (Fig. 1A). In a part of tumor, neoplastic cells with marginally located nucleus in the vacuolated cytoplasm showed palisade arrangement at the periphery of cellular nests mimicking seminiferous tubules (Sertoli cell tumor portion; Fig. 1B). Cellular proliferation with indistinct cellular border was also observed in this tumor portion. Neoplastic cells typically have round to oval shaped nuclei containing one or two distinct nucleoli with minor cellular atypia, and occasional mitotic figures were also observed. Irrespective of the histological type of tumor, neoplastic cells contain numerous tiny vacuoles positive for PAS or Sudan IV in cryosections (Fig. 1C and 1D). The PAS-positivity largely disappeared in regularly paraffin-embedded tissue sections (Fig. 1E). Immunohistochemical analysis revealed that neoplastic cells in the luteoma portion were mostly and strongly positive for inhibin $\alpha$ in the cytoplasm (Fig. 2A), WT1 (Fig. 2C) in the nucleus and NSE in the cytoplasm (Fig. 2E). Neoplastic cells in the Sertoli cell tumor portion showed similar intense immunoreactivity for inhibin $\alpha$ (Fig. 2B) and NSE (Fig. 2F), but they were negative for WT1 (Fig. 2D). Sertoli cells in the dog testis showed scattered cytoplasmic immunoreactivity for inhibin $\alpha$ and diffuse cytoplasmic immunoreactivity for NSE, but they were negative for WT-1. Ovary showed diffuse positive immunoreactivity for all inhibin $\alpha$, WT-1, and NSE in the granulosa cells, while WT-1 alone showed positive immunoreactivity in the follicular theca cells. Neoplastic cells did not show any vascular invasion as revealed by immunostaining of endothelial cells using anti-von Willebrand factor antibody.

The present case exhibited typical histological nature of neoplastic cells featured with centrally located nucleus inside of the abundant and vacuolated cytoplasm with distinct cellular border and showed a growth pattern forming various sized cellular nests fusing each other. Because there was no granulosa cell component, the present case was primarily diagnosed as luteoma. In human, different from pregnancy luteomas [23], luteomas developed in postmenopausal women are rare benign steroid cell neoplasms $[9,24]$. These neoplasms are believed to be of stromal derivation, originating from luteinized cells or their precursors, undifferentiated spindle cells of the ovarian stroma, and they are often diagnosed as luteinized granulosa cell tumors $[4,24]$. In dogs, there have been no case reports of ovarian luteomas except for one study of steroid cell tumor resembling luteoma associated with hyperadrenocortism in a bitch [29]. The present case exhibited abnormal vaginal bleeding that is known to be the most frequent clinical manifestation of granulosa cell tumors and luteomas [26, 28-30]. Interestingly, development of granulosa cell tumors has been reported in spayed bitches as in the present case $[20,26]$. One of them showed a predominance of lobules of luteallike cells accompanied by granulosa cells proliferating in a Sertoli cell pattern [26].

In the present case, some portions of neoplastic cells showed Sertoli cell tumor morphology with palisade cellular arrangement at the margin of cellular nests mimicking seminiferous tubules or diffuse cellular proliferation showing indistinct cellular borders. Luteoma cells contain lipid vacuoles and Sertoli cell tumor cells contain glycogen granules [5, 9]. In the present study, both PAS and Sudan IV stainings showed fine granular positive reactions in cryosections. With regard to PAS-positive fine granular staining pattern, it largely disappeared in paraffin-embedded tissue samples. These results indicate that neoplastic cells contain both glycogen granules and lipid droplets, irrespective of the histological type of tumor, suggesting a complex cellular nature of neoplastic cells showing both luteoma and Sertoli cell tumor characteristics. Although occasional mitotic figures were found, no apparent invasiveness involving vasculature indicates benign nature of this tumor.

Inhibin $\alpha$, a gonadal glycopeptide known to be a feedback inhibitor of pituitary secretion of follicle-stimulating hormone, is a useful marker of canine [14] and human sex cordstromal tumors $[15,17,31]$. Inhibin $\alpha$ is not expressed in other types of canine ovarian tumors such as epithelial or germ cell tumors [14]. However, there still remains a controversial point on the tumor type to express inhibin $\alpha$ in the canine testis. In one study, neoplastic Sertoli cells lacked inhibin $\alpha$ expression [27], but, in other studies, neoplastic Sertoli cells showed its expression [12, 18, 32]. Also, cases with Sertoli cell tumor exhibited high blood concentrations of inhibin $\alpha[8,10]$. In accordance with the latter reported cases, almost all of neoplastic cells in the present case showed a strong immunoreactivity for inhibin $\alpha$ irrespective of tumor type, as well as the positive control case of Sertoli cell tumor. It is also reported that the most of sex cord-stromal tumors, especially of granulosa cell type, show a positive reactivity for inhibin $\alpha$ regardless of their histological malignancy grade [1,21]. Sertoli cells and granulosa cells in normal gonads also showed similar positive reactivity for inhibin $\alpha$ in the present study. Moreover, intense immunoreactivity of inhibin $\alpha$ has been shown in luteinized granulosa cell tumors [22], suggesting that inhibin $\alpha$ expression in the luteoma portion in the present case may be reasonable as with expression in Sertoli cells.

WT1, that has been originally identified as a tumor suppressor gene located at the human chromosome $11 \mathrm{p} 13$ and 

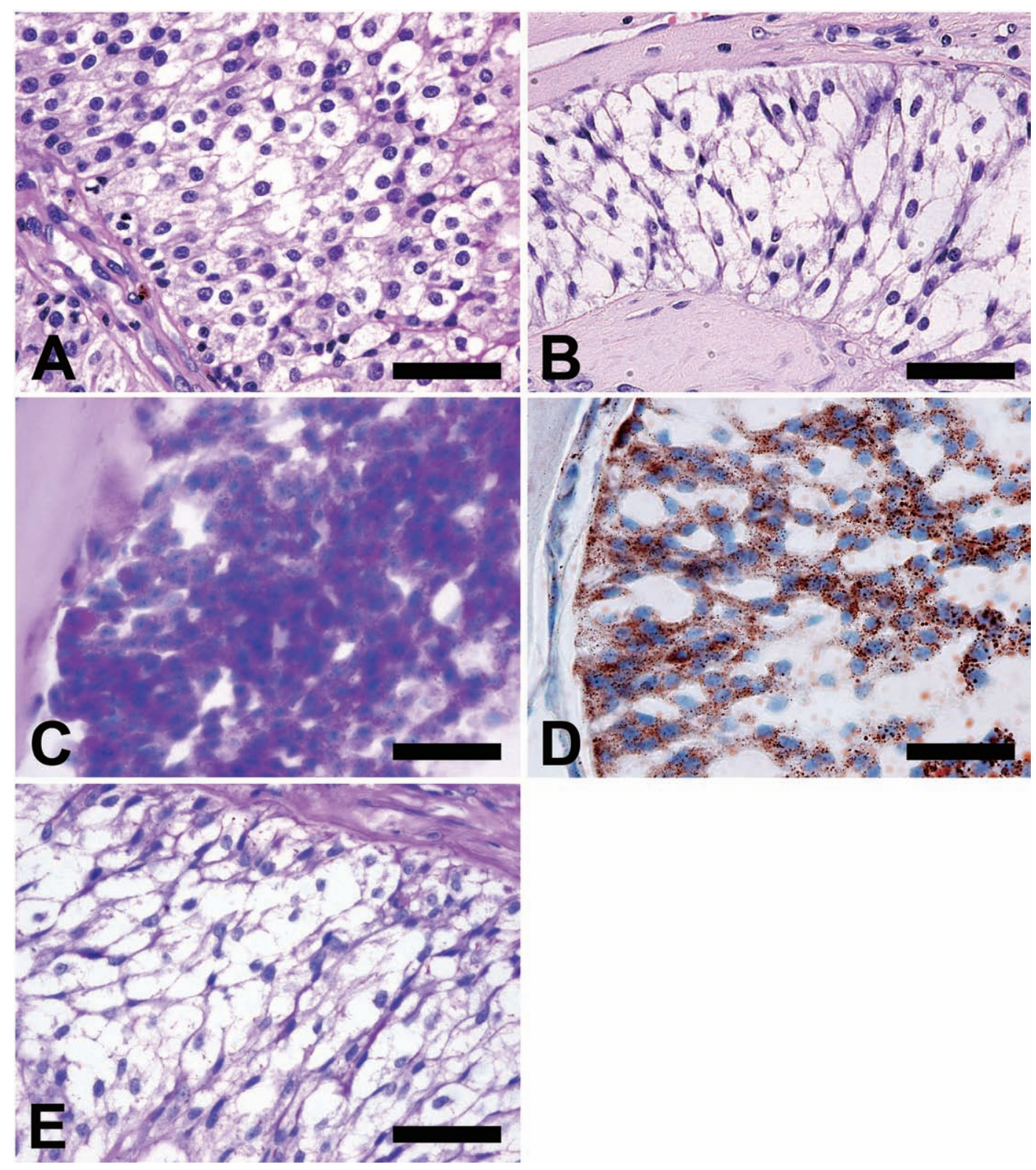

Fig. 1. High-power view of the ovarian tumor in HE, PAS, and Sudan IV stains. A. In the portion of luteoma, diffuse proliferation of neoplastic cells, round to oval in shape and abundant vacuolated cytoplasm with centrally located nucleus and distinct cell borders, is evident to form cellular nest. HE. Bar $=50 \mu \mathrm{m}$. B. In the portion of the Sertoli cell tumor, vacuolated neoplastic cells with marginally located nucleus in the cytoplasm show palisade arrangement into luminal margin mimicking seminiferous tubules. HE. Bar $=50 \mu \mathrm{m}$. C. Cytoplasm of the neoplastic cell shows a positive reactivity for PAS stain in a cryosection. Many PAS-positive cytoplasmic granules are evident. PAS. Bar $=50$ $\mu \mathrm{m}$. D. Cytoplasm of the neoplastic cell shows a positive reactivity for Sudan IV stain in a cryosection. Many Sudan IV-positive cytoplasmic granules are evident. Sudan IV. Bar $=50 \mu \mathrm{m}$. E. PAS-positive granules in the cryosection as shown in panel $\mathrm{C}$ were mostly disappeared in a paraffin-embedded section. PAS. Bar $=50 \mu \mathrm{m}$.

responsible for pediatric renal tumors, is now known as a transcriptional factor that plays an oncogenic role in various kinds of tumors $[3,13]$. In human, this factor is detected in Sertoli-Leydig cell tumors and granulosa cell tumors [7]. In another human case study, on the other hand, WT1-immunoreactivity in Sertoli-Leydig cell tumors has shown to be negative for all cases examined [3]. In the present case, neoplastic cells were exclusively positive for WT1 in the nucleus in the portion of luteoma, whereas the portion of Sertoli cell tumor lacked its expression, similarly to the case of malignant Sertoli cell tumor examined here. While information on the immunoreactivity in ovarian luteal cells is 

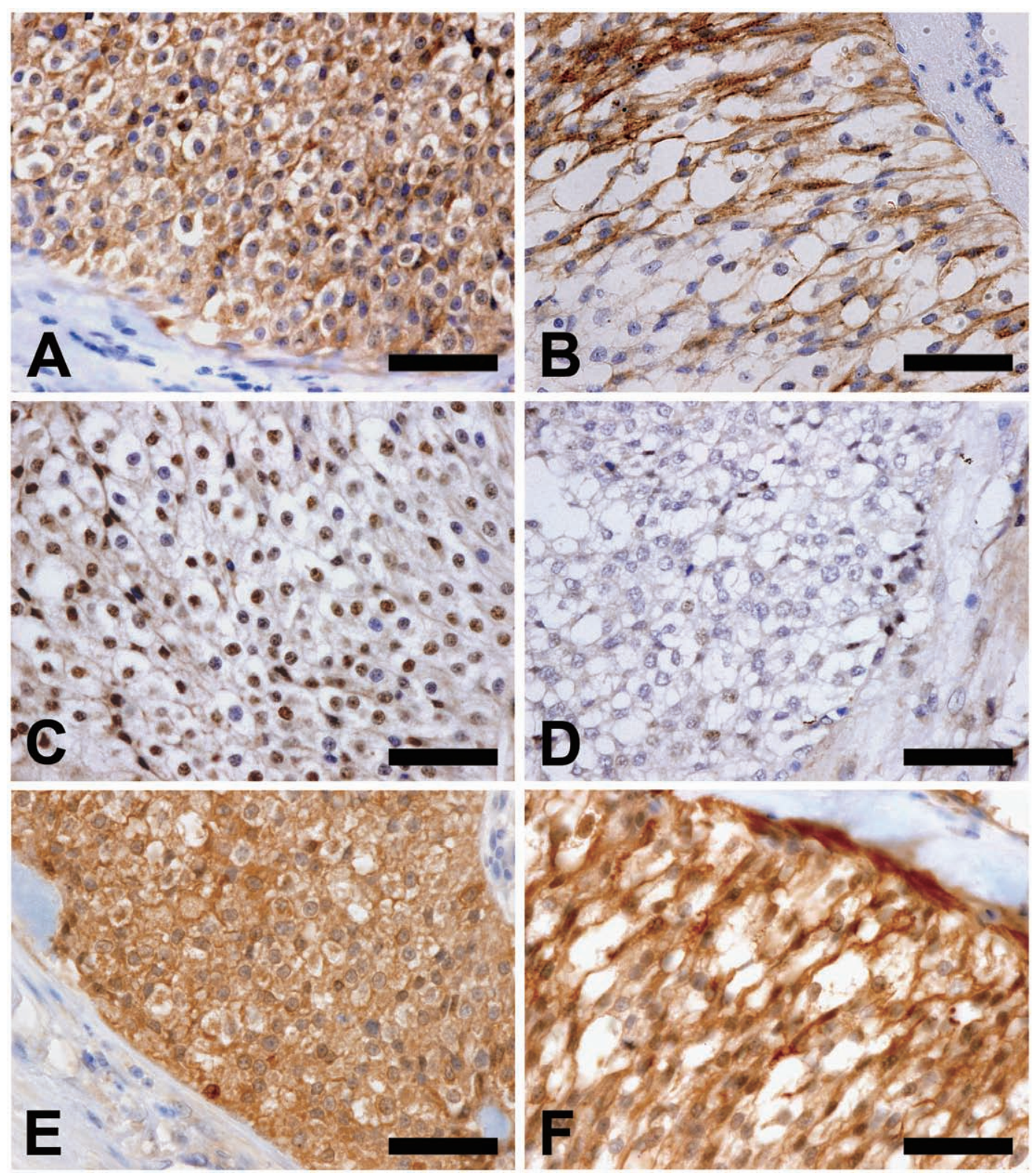

Fig. 2. Immunohistochemical staining results in the luteoma and Sertoli cell tumor portions. A and B. Inhibin $\alpha$ in the portions of luteoma (A) and Sertoli cell tumor (B). Most neoplastic cells show strong immunoreactivity in the cytoplasm in both tumor portions. Bar $=50 \mu \mathrm{m}$. C and D. WT-1 in the portions of luteoma (C) and Sertoli cell tumor (D). Most neoplastic cells in the portion of luteoma show strong nuclear immunoreactivity, while most of neoplastic cells in the portion of Sertoli cell tumor lacked WT1-expression. Bar $=50 \mu \mathrm{m}$. E and F. NSE in the portions of luteoma (E) and Sertoli cell tumor $(\mathrm{F})$. Both tumor portions show strong cytoplasmic immunoreactivity. Bar $=50 \mu \mathrm{m}$.

lacking due to immaturity of the ovary used here, positive immunoreactivity for WT1 in the follicular granulosa and theca cells and lack of this expression in the testicular Sertoli cells may support the difference in the immunoreactivity between the portions of luteoma and Sertoli cell tumor. As well as human cases of granulosa cell tumors, expression of WT1 in our luteoma portion may suggest requirement of WT1 for oncogenicity of granulosa/luteal cells irrespective of the differentiation potential. Lack of WT1-expression in the Sertoli cell tumor portion, in contrast to the surrounding luteoma portion, may reflect a phenotypic change of neoplastic cells in the present case, although co-existence of neoplastic granulosa/luteal cells and Sertoli cells is uncommon in humans.

NSE has been reported to express in normal and neoplastic Sertoli cells in a case report of mixed germ cell and sex 
cord-stromal cell tumor developed in a dog testis [18]. In the present study, both malignant Sertoli cell tumor and luteoma with Sertoli cell tumor portion showed positive immunoreactivity with NSE. We also observed positive immunoreactivity for NSE in the normal testicular Sertoli cells. Although we could not estimate immunoreactivity in the ovarian luteal cells, NSE-immunoreactivity in the luteoma portion of the present case may be the first to show in this tumor type.

In human, minor population of gonadal tumors that are classified into the sex cord-stromal category sometimes cannot be placed in the more specific categories [25]. Typically, uncommon population of gonadal tumors exhibiting hybrid features between the granulosa and Sertoli cell families has been placed in the unclassified group of sex cordstromal tumors $[25,31]$. Although the granulosa cell component was lacking, the present case exhibiting Sertoli cell tumor component within luteoma may fall into the unclassified category of sex cord-stromal tumors. In human, the behavior of these unclassified tumors is similar to that of granulosa and Sertoli-Leydig tumors, with a favorable prognosis when confined to the ovaries [25]. It should be stressed that a minor population of granulosa cell tumors in dogs that were diagnosed according to the World Health Organization (WHO) International Histological Classification of Tumors of the Genital System of Domestic Animals, develop a tubular pattern similar to that of the Sertoli cell tumor of the testis [11]. These cases may be reclassified into unclassified sex cord-stromal tumor that is applied in human cases [25, 31].

In conclusion, we reported here a case of benign ovarian tumor probably arising from the remnant of ovarian tissue after 10 years of ovariectomy. Because of the typical histological feature of neoplastic cells containing numerous Sudan IV-positive lipid droplets in the cytoplasm without concomitant granulosa cell component, this tumor was diagnosed as luteoma. Also, positive immunoreactivity for inhibin $\alpha$ and WT1 may support this diagnosis. Morphologically, a part of the tumor showed Sertoli cell tumor-like nests, and PAS-positive cytoplasmic granules suggestive of glycogen and NSE-immunoreactivity may support Sertoli cell phenotype. Furthermore, lack of WT1 in neoplastic cells may be the signature of phenotype change into Sertoli cells. Thus, because of the uncommon hybrid features between the luteal and Sertoli cell populations, this tumor could be placed in the unclassified group of sex cord-stromal tumors if applied in human cases. Further studies on the frequency of occurrence as well as the differentiation potential are needed for this type of sex cord-stromal cell tumors in the ovary of animals.

ACKNOWLEDGMENT(S). We thank Mrs. Shigeko Suzuki for her technical assistance in preparing histological specimens.

\section{REFERENCES}

1. Akihara, Y., Shimoyama, Y., Kawasako, K., Komine, M., Hirayama, K., Kagawa, Y., Omachi, T., Matsuda, K., Okamoto, M., Kadosawa, T. and Taniyama, H. 2007. Immunohistochemical evaluation of canine ovarian tumors. J. Vet. Med. Sci. 69: 703-708.

2. Anderson, A. C. and Simpson, M. E. 1973. pp. 210-224, 245263. In: The Ovary and Reproductive Cycle of the Dog (Beagle), Geron X, Los Altos, CA.

3. Cathro, H. P. and Stoler, M. H. 2005. The utility of calretinin, inhibin, and WT1 immunohistochemical staining in the differential diagnosis of ovarian tumors. Hum. Pathol. 36: 195-201.

4. Chico, A., Garcia, J. L., Matias-Guiu, X., Webb, S. M., Rodriguez, J., Prat, J. and Calaf, J. 1995. A gonadotrophin dependent stromal luteoma: A rare cause of post-menopausal virilization. Clin. Endocrinol. 43: 645-649.

5. Chung, E. Y. 2008. Ultrastructure of germ cells, the Leydig cells, and Sertoli cells during spermatogenesis in Boleophthalmus pectinirostris (Teleostei, Perciformes, Gobiidae). Tissue Cell. 40: 195-205.

6. Cotcin, E. 1961. Canine ovarian neoplasms. Res. Vet. Sci. 2: 133-142.

7. Deavers, M. T., Malpica, A., Liu, J., Broaddus, R. and Silva, E. G. 2003. Ovarian sex cord-stromal tumors: an immunohistochemical study including a comparison of calretinin and inhibin. Mod. Pathol. 16: 584-590.

8. Grootenhuis, A. J., van Sluijs, F. J., Klaij, I. A., Steenbergen, J., Timmerman, M. A., Bevers, M. M., Dieleman, S. J. and de Jong, F. H. 1990. Inhibin, gonadotrophins and sex steroids in dogs with Sertoli cell tumours. J. Endocrinol. 127: 235-242.

9. Hayes, M. C. and Scully, R. E. 1987. Stromal luteoma of the ovary: a clinicopathological analysis of 25 cases. Int. J. Gynecol. Pathol. 6: 313-321.

10. Kawakami, E., Hirano, T., Hori, T. and Tsutsui, T. 2007. Testicular superoxide dismutase activity, heat shock protein 70 concentration and blood plasma inhibin-alpha concentration of dogs with a Sertoli cell tumor in a unilateral cryptorchid testis. J. Vet. Med. Sci. 69: 1259-1262.

11. Kennedy, P. C., Cullen, J. M., Edwards, J. F., Goldschmidt, M. H., Larsen, S., Munson, L. and Nielsen, S. 1999. Histological Classification of Tumors of the Genital System of Domestic Animals. pp. 24-25. In: World Health Organization, International Histological Classification of Tumors of Domestic Animals, 2nd series, vol. IV (Shulman, F. Y. ed.), The Armed Forces Institute of Pathology, Washington, D. C.

12. Kommoss, F., Oliva, E., Bittinger, F., Kirkpatrick, C. J., Amin, M. B., Bhan, A. K., Young, R. H. and Scully, R. E. 2000. Inhibin-alpha CD99, HEA 125, PLAP, and chromogranin immunoreactivity in testicular neoplasms and the androgen insensitivity syndrome. Hum. Pathol. 31: 1055-1061.

13. Lee, S. B. and Haber, D. A. 2001. Wilms tumor and the WT1 gene. Exp. Cell. Res. 264: 74-99.

14. Marino, G., Nicòtina, P. A., Catone, G., Bontempo, R. A. and Zanghì, A. 2003. Alpha-inhibin expression in canine ovarian neoplasms: preliminary results. Vet. Res. Commun. 27: 237240.

15. Mooney, E. E., Nogales, F. F., Bergeron, C. and Tavassoli, F. A. 2002. Retiform Sertoli-Leydig cell tumours: clinical, morphological and immunohistochemical findings. Histopathology 41: 110-117.

16. Norris, H. J., Garner, F. M. and Taylor, H. B. 1970. Comparative pathology of ovarian neoplasms. IV. Gonadal stromal 
tumours of canine species. J. Comp. Pathol. 80: 399-405.

17. Oliva, E., Alvarez, T. and Young, R. H. 2005. Sertoli cell tumors of the ovary: a clinicopathologic and immunohistochemical study of 54 cases. Am. J. Surg. Pathol. 29: 143156.

18. Owston, M. A. and Ramos-Vara, J. A. 2007. Histologic and immunohistochemical characterization of a testicular mixed germ cell sex cord-stromal tumor and a leydig cell tumor in a dog. Vet. Pathol. 44: 936-943.

19. Patnaik, A. K. and Greenlee, P. G. 1987. Canine ovarian neoplasms: a clinicopathologic study of 71 cases, including histology of 12 granulosa cell tumors. Vet. Pathol. 24: 509-514.

20. Pluhar, G. E., Memon, M. A. and Wheaton, L. G. 1995. Granulosa cell tumor in an ovariohysterectomized dog. J. Am. Vet. Med. Assoc. 207: 1063-1065.

21. Riccardi, E., Grieco, V., Verganti, S. and Finazzi, M. 2007. Immunohistochemical diagnosis of canine ovarian epithelial and granulosa cell tumors. J. Vet. Diagn. Invest. 19: 431-435.

22. Rishi, M., Howard, L. N., Bratthauer, G. L. and Tavassoli, F. A. 1997. Use of monoclonal antibody against human inhibin as a marker for sex cord-stromal tumors of the ovary. Am. J. Surg. Pathol. 21: 583-589.

23. Roth, L.M. 2006. Recent advances in the pathology and classification of ovarian sex cord-stromal tumors. Int. J. Gynecol. Pathol. 25: 199-215.

24. Scully, R. E. 1964. Stromal luteoma of the ovary-a distinctive type of lipoid-cell tumour. Cancer 17: 769-778.

25. Seidman, J. D. 1996. Unclassified gonadal stromal tumors: a clinicopathologic study of 32 cases. Am. J. Surg. Pathol. 20:
699-706.

26. Sivacolundhu, R. K., O'Hara, A. J. and Read, R. A. 2001. Granulosa cell tumour in two spayed bitches. Aust. Vet. J. 79: 173-176.

27. Taniyama, H., Hirayama, K., Nakada, K., Numagami, K., Yaosaka, N., Kagawa, Y., Izumisawa, Y., Nakade, T., Tanaka, Y., Watanabe, G. and Taya, K. 2001. Immunohistochemical detection of inhibin-alpha, -betaB, and -betaA chains and 3beta-hydroxysteroid dehydrogenase in canine testicular tumors and normal testes. Vet. Pathol. 38: 661-666.

28. Vilain, M. O., Cabaret, V., Delobelle-Deroide, A., Duminy, F. and Laurent, J. C. 1992. Stromal luteoma of the ovary. Differential diagnosis of steroid cell tumors. Ann. Pathol. 12: 193197 (in French).

29. Yamini, B., VanDenBrink, P. L. and Refsal, K. R. 1997. Ovarian steroid cell tumor resembling luteoma associated with hyperadrenocorticism (Cushing's disease) in a dog. Vet. Pathol. 34: 57-60.

30. Young, R. H., Oliva, E. and Scully, R. E. 1994. Luteinized adult granulosa cell tumors of the ovary: a report of four cases. Int. J. Gynecol. Pathol.13: 302-310.

31. Young, R. H. 2005. Sex cord-stromal tumors of the ovary and testis: their similarities and differences with consideration of selected problems. Mod. Pathol. 18: S81-98.

32. Yu, C. H., Hwang, D. N., Yhee, J. Y., Kim, J. H., Im, K. S., Nho, W. G., Lyoo, Y. S. and Sur, J. H. 2009. Comparative immunohistochemical characterization of canine seminomas and Sertoli cell tumors. J. Vet. Sci. 10: 1-7. 